\title{
Microcirculatory alterations after cardiopulmonary bypass as assessed with near infrared spectroscopy: a pilot study
}

\author{
Elli-Sophia Tripodaki, MD • Athanasios Tasoulis, MD • Ioannis Vasileiadis, MD • \\ Leonidas Vastardis, MSc • Neoklis Skampas, MD • Timotheos Sakellaridis, MD • \\ Mihalis Argiriou, MD $\cdot$ Christos Charitos, MD $\cdot$ Serafim Nanas, MD
}

Received: 30 May 2011/ Accepted: 23 February 2012/Published online: 10 March 2012

(c) Canadian Anesthesiologists' Society 2012

\section{To the Editor,}

Cardiac surgery under cardiopulmonary bypass (CPB) may induce changes in microvascular perfusion and compromise peripheral tissue oxygenation. ${ }^{1,2}$ Near infrared spectroscopy (NIRS) is an easily applicable noninvasive technique that has been used in combination with the vascular occlusion technique (VOT) for the evaluation of the microcirculation. ${ }^{3,4}$ We hypothesized that NIRS and VOT are able to detect the microcirculatory alterations of cardiac surgical patients.

After obtaining institutional ethics approval and written informed consent, we conducted a pilot study in nine cardiac surgery patients (three males/ six females). Characteristics of the patients were: age 67 (13), EuroSCORE 6.4 (3.8), left ventricular ejection fraction 58 (9) \%, CPB duration 129 (47) min, aortic cross-clamp time 66 (20) min. All patients were anesthetized and their lungs ventilated in a similar manner throughout the monitoring period. The doses of vasopressors/inotropes and propofol did not change during the monitoring period. Near infrared spectroscopy measurements were performed (InSpectra; Hutchinson Technology, Hutchinson, MN, USA) on the day prior to surgery,

E.-S. Tripodaki, MD · A. Tasoulis, MD · I. Vasileiadis, MD . S. Nanas, MD $(\bowtie)$

Evangelismos Hospital, National and Kapodistrian University of Athens, Athens, Greece

e-mail: a-icu@med.uoa.gr

L. Vastardis, MSc - T. Sakellaridis, MD - M. Argiriou, MD .

C. Charitos, MD

Evangelismos Hospital, 2nd Department of Cardiac Surgery, Athens, Greece

N. Skampas, MD

3rd IKA Hospital, Athens, Greece postoperatively on admission to the intensive care unit, and every two hours for six hours. Tissue oxygen saturation $\left(\mathrm{StO}_{2} \%\right)$ of the thenar eminence was monitored and a brachial VOT was utilized to better assess the microcirculation with the calculation of the oxygen consumption rate and the reperfusion rate.

The results of this pilot study are shown in the accompanying Table. Immediately after CPB there were abnormalities in skeletal muscle tissue oxygenation and utilization which normalized at six hours (Table A). Conversely, the global hemodynamic variables did not change significantly in this six-hour monitoring period (Table B).

This pilot study indicates that NIRS can detect microvascular derangements whereas routine global measurements seem to be insensitive.

Cardiac surgery with CPB induces physiological alterations: ${ }^{5}$ the blood is exposed to artificial surfaces, nonpulsatile flow is the norm, the myocardium is arrested with cold cardioplegic protection, and body temperature is lowered by several degrees. These features, in combination with the surgical trauma, contribute to an intense inflammatory reaction resulting in the activation of endothelial cells, leukocytes, platelets, the complement system, and the coagulation cascade. Endothelial dysfunction and the loss of endothelium-dependent vasodilation can lead to the "noreflow" phenomenon and amplify tissue injury. This report shows that NIRS-derived variables depict this local derangement. The improvement of microcirculatory indices during the ensuing hours can be attributed to the restoration of the microcirculation as the hours after surgery progress. Importantly, this report also shows that routine monitors do not reflect these microvasculature abnormalities.

Future studies are needed to investigate the possibility of reversing these NIRS-derived microcirculation variables and whether these are important clinical end points. 
Table A Microcirculation variables assessed preoperatively, after admission to the intensive care unit $\left(\mathrm{H}_{0}\right)$, and every two hours for six hours $\left(\mathrm{H}_{2}, \mathrm{H}_{4}, \mathrm{H}_{6}\right)$

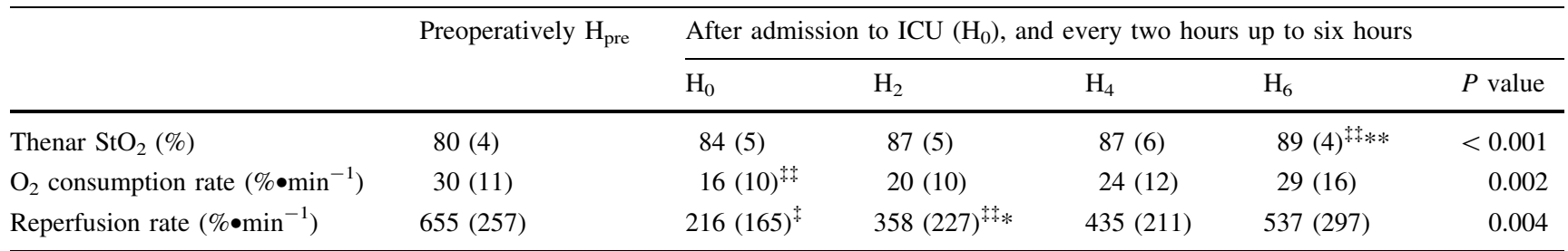

ICU $=$ intensive care unit; $\mathrm{StO}_{2}=$ tissue oxygen saturation. ${ }^{\star} P<0.01$ from $\mathrm{H}_{\text {pre}}$; ${ }^{*} P<0.05$ from $\mathrm{H}_{\mathrm{pre}} ; * P<0.01$ from $\mathrm{H}_{0}$; $* * P<0.05$ from $\mathrm{H}_{0}$. Data presented as mean (standard deviation)

Table B Hemodynamic data, pressures, lactate concentrations, and temperatures after ICU admission $\left(\mathrm{H}_{0}\right)$ and every two hours for six hours $\left(\mathrm{H}_{2}, \mathrm{H}_{4}, \mathrm{H}_{6}\right)$

\begin{tabular}{|c|c|c|c|c|c|}
\hline & $\mathrm{H}_{0}$ & $\mathrm{H}_{2}$ & $\mathrm{H}_{4}$ & $\mathrm{H}_{6}$ & $P$ value \\
\hline $\mathrm{CO}\left(\mathrm{L} \cdot \min ^{-1}\right)$ & $4.2(1.1)$ & $4.7(1.3)$ & $4.4(0.6)$ & $4.9(1.1)$ & \\
\hline $\mathrm{CI}\left(\mathrm{L} \cdot \mathrm{min}^{-1} \cdot \mathrm{m}^{-2}\right)$ & $2.3(0.6)$ & $2.7(0.8)$ & $2.5(0.3)$ & $2.8(0.7)$ & \\
\hline PCWP (mmHg) & $11(4.6)$ & $12.5(4.1)$ & $10.5(3.8)$ & $11.2(6)$ & \\
\hline CVP (mmHg) & $7.2(4.3)$ & $8.9(3.9)$ & $8.7(3.8)$ & $9(4.4)$ & \\
\hline SVR (dynes-s/cm5) & $1,520(482)$ & $1,189(393)$ & $1,277(321)$ & $1,162(347)$ & 0.035 \\
\hline PVR (dynes-s/cm5) & $249(95)$ & $189(73)$ & $350(301)$ & $219(61)$ & \\
\hline $\mathrm{SvO}_{2}(\%)$ & $69(7)$ & $66(8)$ & $64(8)$ & $65(10)$ & \\
\hline $\mathrm{ScvO}_{2}(\%)$ & $72(8)$ & $68(9)$ & $66(10)$ & $68(10)$ & \\
\hline $\mathrm{Hb}\left(\mathrm{mmol} \cdot \mathrm{L}^{-1}\right)$ & $7.4(1.1)$ & $7.1(1.1)$ & $7(1.4)$ & $6.9(1.1)$ & \\
\hline $\mathrm{Lac}\left(\mathrm{mg} \cdot \mathrm{dL}^{-1}\right)$ & $2.9(2.2)$ & $3.5(2.9)$ & $3.8(3.1)$ & $3.9(2.7)$ & 0.042 \\
\hline MAP (mmHg) & $83(13)$ & $74(11)$ & $78(16)$ & $76(12)$ & \\
\hline MPP (mmHg) & $22(7)$ & $23(6)$ & $28(16)$ & $24(8)$ & \\
\hline Central temperature $\left({ }^{\circ} \mathrm{C}\right)$ & $36.4(0.7)$ & $36.9(0.6)$ & $37.5(0.4)^{* *}$ & $37.8(0.4)^{* *}$ & $<0.001$ \\
\hline Peripheral temperature $\left({ }^{\circ} \mathrm{C}\right)$ & $35.8(0.7)$ & $36.3(0.6)$ & $36.9(0.6)^{* \$}$ & $37.2(0.5)^{* \S}$ & $<0.001$ \\
\hline Central-Peripheral temperature $\left({ }^{\circ} \mathrm{C}\right)$ & $0.53(0.39)$ & $0.42(0.19)$ & $0.52(0.29)$ & $0.45(0.24)$ & \\
\hline
\end{tabular}

$\mathrm{CI}=$ cardiac index $\mathrm{CO}=$ cardiac output; $\mathrm{CVP}=$ central venous pressure $\mathrm{Hb}=$ hemoglobin; $\mathrm{ICU}=$ intensive care unit; Lac $=$ lactate; $\mathrm{MAP}=$ mean arterial pressure; $\mathrm{MPP}=$ mean pulmonary pressure; PCWP $=$ pulmonary capillary wedge pressure; $\mathrm{PVR}=$ pulmonary vascular resistance; $\mathrm{ScvO}_{2}=$ central venous oxygen saturation; $\mathrm{SvO}_{2}=$ mixed venous oxygen saturation. $\mathrm{SVR}=$ systematic vascular resistance, temp $=$ temperature. $* P<0.01$ from $\mathrm{H}_{0} ; * * P<0.05$ from $\mathrm{H}_{0} ;{ }^{\S} \mathrm{P}<0.01$ from $\mathrm{H}_{2}$; Data presented as mean (standard deviation)

Acknowledgements The authors sincerely thank the nursing and medical staff of the cardiac intensive care unit of Evangelismos hospital for their professionalism and dedication to patient care.

Competing interests None declared.

\section{References}

1. Bouchet JB, Durand E, Morel J, et al. Microcirculatory dysfunction after cardiac surgery: interest of NIRS technology with two case reports (French). Ann Fr Anesth Réanim 2011; 30: 589-93.
2. Uilkema RJ, Groeneveld AB. Correlates of thenar near-infrared spectroscopy-derived tissue $\mathrm{O}_{2}$ saturation after cardiac surgery. Interact Cardiovasc Thorac Surg 2007; 6: 265-9.

3. Nanas $S$, Gerovasili V, Renieris $P$, et al. Non-invasive assessment of the microcirculation in critically ill patients. Anaesth Intensive care 2009; 37: 733-9.

4. Gerovasili V, Tripodaki E, Karatzanos E, et al. Short-term systemic effect of electrical muscle stimulation in critically ill patients. Chest 2009; 136: 1249-56.

5. McGuinness J, Bouchier-Hayes D, Redmond JM. Understanding the inflammatory response to cardiac surgery. Surgeon 2008; 6: 162-71. 